\title{
Instruments and Institutions for Groundwater Management
}

\author{
Karin ERIKa Kemper \\ World Bank (South Asia Sustainable Development Department), $1818 \mathrm{H}$ \\ Street NW, Washington, DC 20433, USA
}

Groundwater is one of the key resources enabling agricultural development, providing farmers from Argentina and India to China with access and flexibility in water application that usually cannot be matched by surface water resources unless a farmer lives in close proximity to a perennial river or lake. No wonder, therefore, that groundwater is so popular in agriculture, as already highlighted in the regional chapters in this volume. In fact, groundwater irrigation now surpasses surface water as the main source of irrigation water in many regions. Because of the growth in groundwater irrigation, agriculture now accounts for an estimated $70 \%$ of total groundwater use with only $20 \%$ and $10 \%$ going to industry and residential uses, respectively (Brown et al., 1999). However, the large-scale expansion in agricultural groundwater use is leading to the resource being overexploited in an increasing number of countries. Intensive exploitation of groundwater for agricultural uses in India, China, North Africa and the Arabian peninsula exceeds natural replenishment by at least 160 billion cubic metres per year (www.wateryear2003.org).

While published cases of agricultural groundwater use and overuse are impressive, it is important to note that groundwater in some hydrogeological settings is not used alone, but in conjunction with surface water, for instance, as a supplement when irrigation schemes are undermanaged and farmers seek reliability and flexibility provided by their own wells. This, added to the fact that rural groundwater use is generally unmonitored, means that worldwide use in agriculture is probably underestimated - as highlighted in the work on South Asia, China and sub-Saharan Africa in this volume - because often only 'pure groundwater irrigation areas' are counted.

The development of drilling technology allowed the spreading of intensive groundwater abstraction in agriculture since the 1970s. This was not accompanied simultaneously by the evolution of institutional arrangements and investments in management agencies. In most countries, groundwater has therefore traditionally been dealt with in a laissez-faire mode, i.e. farmers, be it in Brazil or Pakistan, have used groundwater to irrigate their crops, typically without attention to the 
sustainability of the resource. The effect has been twofold. On the one hand, this unregulated groundwater use has permitted spectacular expansion of agricultural growth and lifted millions of people out of poverty (World Bank, 2005). On the other hand, many aquifers worldwide are now under severe stress and groundwater cannot wholly sustain the production that has been initiated. In these overexploited areas, it has also become clear that introducing aquifer management is a time-consuming and politically challenging endeavour. As this chapter shows, there are a number of countries worldwide that have started to proactively manage their groundwater resources. However, there are as yet few well-established examples of good practices and effective groundwater management in developing countries. Even more than in regard to surface water management, groundwater institutions are in an evolutionary phase and no simple blueprints for management success are appropriate. The reasons for this state of affairs which relate primarily to the nature of the groundwater resource itself will be amply discussed below.

The objective of this chapter is to (i) discuss the special nature of groundwater and the resulting challenges for its effective management in agriculture; (ii) provide an overview of the institutional arrangements and instruments available for groundwater management in a variety of settings worldwide; and (iii) highlight some key issues regarding the way forward in groundwater management for the future.

The paper focuses primarily on the quantity dimension of groundwater overabstraction and briefly touches on pollution management issues, which are even more complex.

\section{What Do We Mean by Instruments and Institutions for Groundwater Management?}

Institutional arrangements, here for short called 'institutions', are described as the 'rules of the game' (North, 1990) within which stakeholders act. They include formal laws and regulations, informal norms and organizations. In the context of groundwater management, we can imagine national or state water laws dealing with groundwater, irrigation laws, their regulations and decrees, as well as norms developed and applied in communities or irrigation command areas regarding groundwater development and use (well construction and spacing norms, water abstraction rules, etc.). These latter norms may be written or informal.

Such institutional arrangements, whether devised at national, state, provincial or community levels, and whether formal or informal, define and affect instruments devised to manage groundwater. Typical instruments include groundwater use rights, abstraction permits or concessions, groundwater tariffs, subsidies and, to a certain extent, groundwater markets. These instruments are called direct instruments, given that they are designed to directly affect groundwater management decisions by stakeholders. Importantly, however, there is also a range of indirect instruments that stem from other sectors, but that have an impact on groundwater use, such as energy pricing, agricultural produce pricing and trade policies (Kemper, 2003).

A further important ingredient in the institutional framework is the organizational form for groundwater management. For instance, in most countries, groundwater is formally managed by government agencies, often at the central 


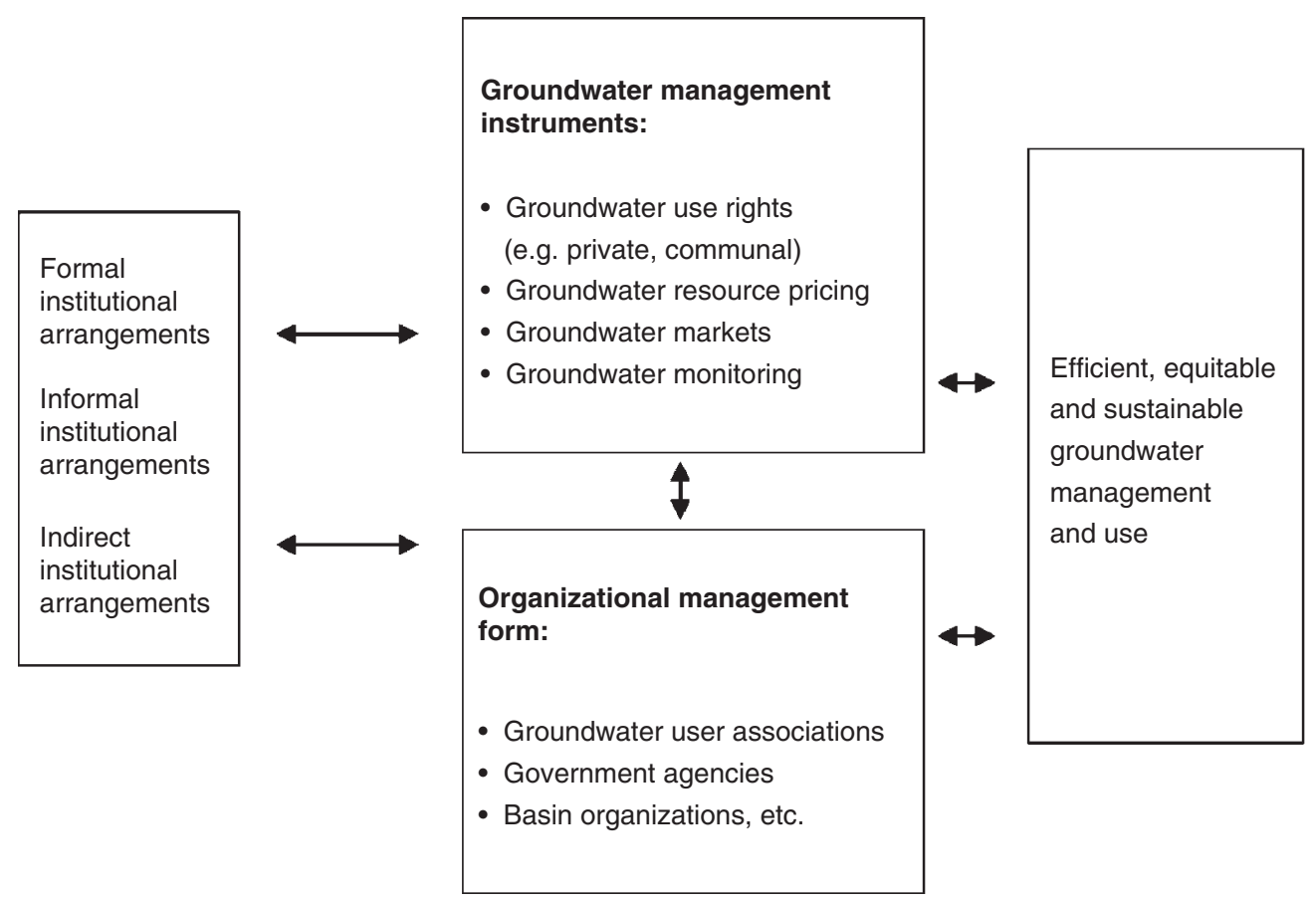

Fig. 8.1. Schematic of the institutional framework for groundwater management.

and sometimes at a lower administrative level. With increasing groundwater scarcity problems, however, aquifer management organizations, which consist of local stakeholders, have started to develop. This tends to coincide with changes in the laws governing groundwater management, but can also happen spontaneously.

Figure 8.1 illustrates schematically how all of the above constitute the institutional framework that conditions groundwater management, with the different institutional arrangements, instruments and organizational forms influencing each other. This chapter provides an overview of the 'menu of institutional ingredients' that can be combined in a variety of ways in order to achieve improved groundwater management, depending on the specific characteristics of an aquifer, a country or a region. The chapter also highlights the importance of the organizational management form with regard to the expectations that one would have concerning the performance of an institutional framework for groundwater management.

\section{In Which Way Are the Challenges for Groundwater Management Different from Those for Surface Water?}

\section{The decentralized nature of groundwater use}

In addition to being invisible, groundwater is a 'horizontal' resource (in spite of the verticality of wells that abstract groundwater from aquifers), i.e. farmers 
located above an aquifer can sink wells independently of each other over a significant areal extension depending on the size of the aquifer. For example, in Mexico some aquifers have an area of only a few square kilometres, whereas the Guarani aquifer system in South America has an area of 1.2 million square kilometres, i.e. the size of England, France and Spain combined (World Bank, 2003).

Therefore, groundwater as a resource - in a situation of abundance - is distributed in an equitable manner to those above a given aquifer. With the less-pronounced upstream-downstream dimension, which is so defining in surface water management, and where upstream users literally have the upper hand over downstream users, the groundwater management challenge is a radically different one. The key issue is to manage a pool resource, which any user who can afford a deep enough well has access to and which therefore can provide benefits to many, but with the focus to make it last for as many users as possible for as long as possible. Groundwater management therefore implies dealing with decentralized stakeholders who will make their decisions based on private utility, weighing their costs (sinking the well, variable abstraction costs, etc.) and their benefits (well yields, type of use, benefit derived from it, etc.). Compared to surface water management, there is no 'tap' in the form of a reservoir release or an irrigation gate intake that can control water access.

The management challenges vary, of course, from country to country and between regions within countries. The manageability of groundwater will depend on the size of the countries and of aquifers, aquifer yields, storage capacity, population density and abstraction for agriculture (since agriculture is usually the primary purpose with the largest number of users, it will have the most impact on management challenges) (Table 8.1).

The categories shown in Table 8.1 only serve as abstracts and in practice assessments will differ. Aquifers vary not only in their spatial dimensions, but also in their yields and recharge profiles. Just so do groundwater users differ, and sociopolitical settings, which influence institutional options for aquifer management, will diverge as much as aquifer characteristics. Aquifer management strategies will therefore have to be developed accordingly. The key point is, however, that the more the actors need to be involved and monitored and the more the abstraction is compared to yield, the higher will be the transaction costs to devise and implement institutional arrangements for aquifer management, and therefore the bigger the challenge to manage the aquifer in a sustainable manner.

The need for groundwater management instruments changes over time. As illustrated in Fig. 8.2, there is a logical progression to groundwater management needs (also compare with Fig. 2.5 by Shah, Chapter 2, this volume).

The figure depicts a typical curve for aquifer management needs, ranging from the baseline situation where groundwater is abundant compared to abstraction to a high-stress situation where abstraction has turned excessive and is leading to irreversible aquifer deterioration. While many will agree that groundwater management is needed in the high-stress situation in order to return to the more 
Table 8.1. Management implications for some types of aquifer-groundwater user relationships.

\begin{tabular}{|c|c|c|}
\hline & $\begin{array}{l}\text { Low density of agricultural } \\
\text { groundwater users and } \\
\text { low abstraction rate } \\
\text { compared to recharge }\end{array}$ & $\begin{array}{l}\text { High density of agricultural } \\
\text { groundwater users and high } \\
\text { abstraction rate compared to } \\
\text { recharge }\end{array}$ \\
\hline Small/medium aquifer & $\begin{array}{l}\text { Low transaction costs in } \\
\text { developing and enforcing } \\
\text { institutional arrangements } \\
\text { for groundwater } \\
\text { management; few } \\
\text { instruments (e.g. } \\
\text { monitoring network) } \\
\text { needed } \\
\text { Example: many aquifers in } \\
\text { sub-Saharan Africa }\end{array}$ & $\begin{array}{l}\text { Medium to high transaction } \\
\text { costs to institute groundwater } \\
\text { management, but probably } \\
\text { manageable due to small } \\
\text { areal extent of intervention } \\
\text { needed; however, need for } \\
\text { groundwater management in } \\
\text { order to ensure sustainability } \\
\text { Example: some Mexican } \\
\text { aquifers }\end{array}$ \\
\hline Large/extensive aquifer & $\begin{array}{l}\text { Possibly higher transaction } \\
\text { costs in developing and } \\
\text { enforcing institutional } \\
\text { arrangements for } \\
\text { groundwater management } \\
\text { due to spatial distribution; } \\
\text { but few instruments } \\
\text { needed while abstraction } \\
\text { remains low } \\
\text { Example: Guarani aquifer } \\
\text { system }\end{array}$ & $\begin{array}{l}\text { If extensive, major aquifer: } \\
\text { Very high transaction } \\
\text { costs to institute effective } \\
\text { groundwater management, } \\
\text { both to achieve agreement } \\
\text { on the institutional framework } \\
\text { and to enforce and monitor } \\
\text { Example: North China Plain } \\
\text { If extensive, but low- } \\
\text { permeability aquifer: } \\
\text { High transaction costs due to } \\
\text { high density of users; but low } \\
\text { transaction costs because } \\
\text { aquifer could be managed as } \\
\text { local units } \\
\text { Example: Indian basement }\end{array}$ \\
\hline
\end{tabular}

stable development situation, we clearly face a paradox here. As can be seen in the figure, groundwater management instruments would ideally be employed at any stage of aquifer use. Even in the baseline situation, registration of abstraction wells and springs as well as source mapping are highly recommended, given that transaction costs for doing so are much lower in a situation of few users and sustainable abstraction than in a later stage when stress has set in. A simple network with a number of monitoring points would also provide important information. For instance, the state of Maharashtra, India, has been monitoring groundwater for 30 years. While the groundwater situation 30 years ago probably would not have triggered major concerns, the long-term investment in the monitoring network and data collection is now paying off because the data series provides important information, even if not sufficient to resolve the serious overabstraction problems 


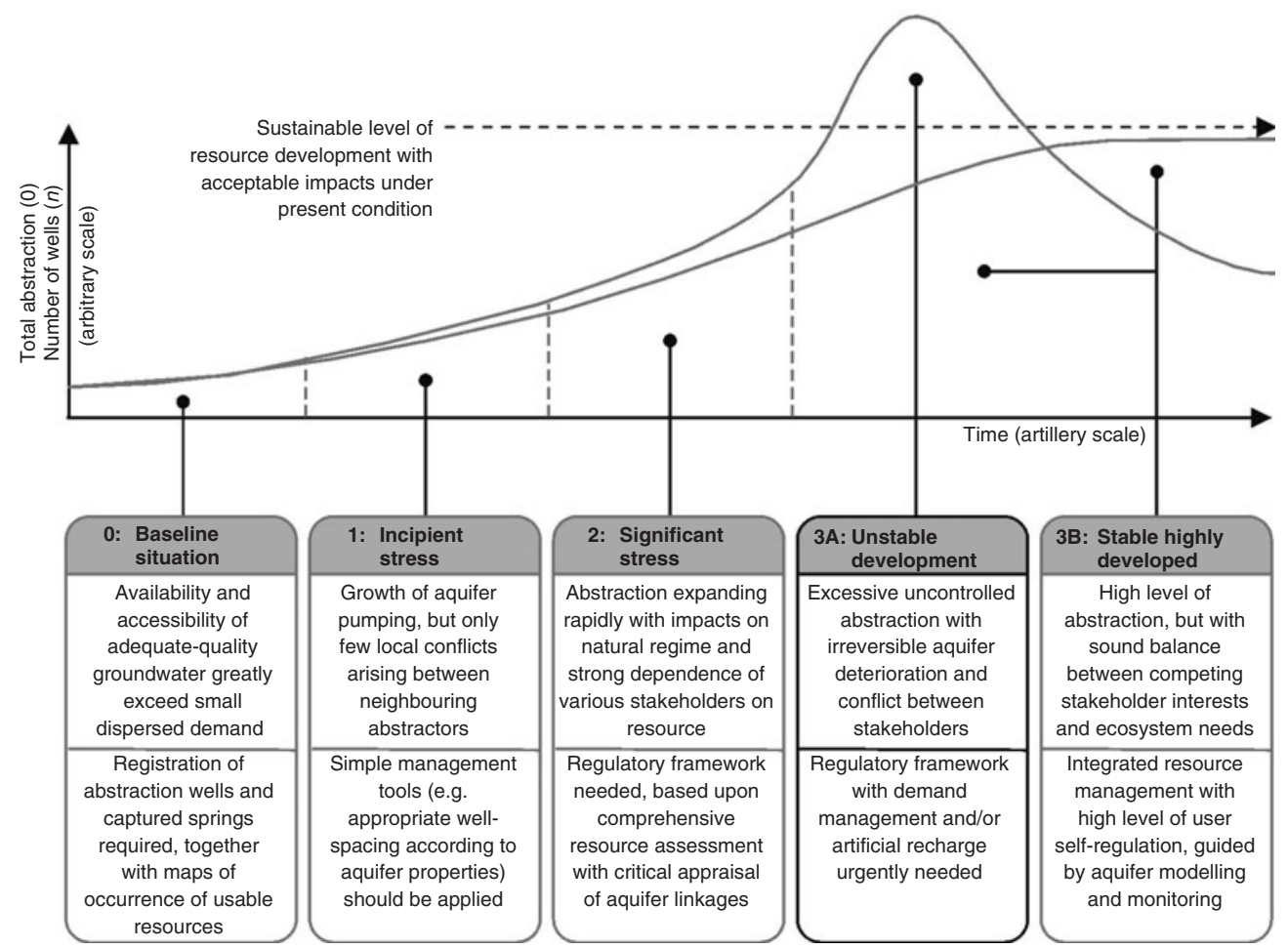

Fig. 8.2. Stages of groundwater resource development in a major aquifer and their corresponding management needs. (From World Bank, 2002-2004.)

managers now face. Regrettably, such basic steps to start building a future aquifer management system are usually not taken. One region where the option still exists is sub-Saharan Africa where groundwater is still abundant in many areas but where development requires scarce financial and human resources to meet many other needs. If action is not taken, once significant stress begins to show and crucial information about users and aquifer yields is required, it may not be available. One possible solution is to improve capture of information already collected. The groundwater development projects in place in many countries in the region generate substantive insight among the drillers and diggers, and the information they create could very well be captured to provide baseline information about aquifers and aquifer users.

Many countries that have not invested in collecting and systematizing such information start only after major aquifer stress appears with the basics, such as well and user registration, measurement or estimation of groundwater abstraction and definition of an entitlement regime, rather than being able to focus on management and fine-tuning of instruments. This way, much valuable time is lost and in many cases it is already too late.

While this chapter primarily focuses on the challenges posed by overabstraction, it is recognized that there are a number of regions in the world where 
groundwater still constitutes a resource to be further developed. Differing examples are presented in discussions on South Asia (Shah et al., Chapter 11, this volume) and Central America (Ballestero et al., Chapter 6, this volume). As pointed out by Shah et al. (2000): '[C]entral to appreciating the global groundwater situation . . . is the coexistence of regions with undeveloped resources and those with overdeveloped resources, and the socioeconomic dynamic that has relentlessly impelled the former to shrink and the latter to expand.'

\section{Equity considerations}

Especially in areas with relatively shallow aquifers, groundwater is a very equitable resource. For instance, the expansion of the treadle pump in India and Bangladesh in recent years shows that low-income farmers can benefit from easy access to groundwater and increase their productivity and economic wellbeing (Shah et al., 2000). In large areas of Africa and South Asia, people dig their own shallow wells or are able to invest in relatively shallow boreholes.

However, when many people do the same in a given area, the many incremental uses can eventually lead to the negative impacts of overabstraction mentioned earlier and reverse the equity effect that originally existed. The first groundwater users who have to abandon their wells as groundwater levels sink can be expected to be the poor who do not have the financial resources to afford pumping water from increasing depths, or to invest in new wells. They are also the first to be hit if their wells turn saline or when their domestic well runs dry or gets polluted. As a consequence, they may have to abandon farming, turn to the city to seek their livelihood or - if they are urban dwellers - start purchasing more expensive water from private vendors (given that the public water supply system frequently does not reach the poor). Even the somewhat richer farmers may experience serious indebtedness if they overinvest to chase a falling water table in shallow aquifers - since their wells are unlikely to generate sufficient income to meet the interest on their loans.

While development efforts and the literature have focused on the access to groundwater and the potential benefits of its use as an equity issue (Kahnert and Levine, 1993), an increasing number of overexploitation and pollution scenarios are now entering the global groundwater agenda. Unfortunately, up to now very few studies have been carried out with regard to the equity impacts of groundwater overexploitation. Such research should provide clues on the costs and benefits of groundwater management actions from a societal point of view. With the prevailing attitude among many groundwater developers that groundwater is a freely exploitable resource, it is always more complex to put simple management measures in place once problems have already arisen. By then vested interests have already developed among users (e.g. relating to amounts of water used and perceived as entitlements, or provision of access to privately developed wells for monitoring purposes) that may make it difficult to develop a clear picture of an aquifer's characteristics and to put in place measures such as monitoring and agreements for more efficient use of the resource. At the same time, groundwater management does entail costs to 
society and to the users, so a balance needs to be found between the cost of management investments compared to the benefits of long-term sustainability of groundwater use (Kemper, 2003).

\section{The 'Menu': What Instruments Can Be Used for Groundwater Management in Agriculture and What Are the Requisite Institutional Arrangements to Make Them Work?}

In this section, the different instruments comprised in the institutional framework - groundwater use rights, monitoring and pricing - will be discussed.

\section{Groundwater use rights, permits, concessions and licensing}

In this chapter, we use the term 'groundwater use rights' as the umbrella expression for any instrument that defines the right of a user to abstract groundwater according to certain parameters, such as volume and duration. Different countries have given these rights different names, such as permits, concessions, licenses and entitlements. All these instruments confer a certain right in a defined way, and what is called a permit in one country and context may be called a concession in another.

Groundwater use rights are often ambiguous and difficult to define. This is due to the previously mentioned difficulty assessing the magnitude and availability of the resource itself. Groundwater modelling is intricate and expensive, and if no good models are available that provide information about available yield over time, the basis for giving any type of water rights, be it concessions or tradable rights, is very weak. Users and water developers' knowledge can be useful to some extent. For example, in Mexico users strongly overstated their water use. Partially as a result, the country is now considering the buy-back of water rights since effectively too many rights were given at the time of initial allocation.

Once groundwater use reaches a certain point with respect to availability, i.e. once the resource becomes scarce, well-defined groundwater use rights can become a key method to control overabstraction, and countries such as the USA ${ }^{1}$ and Mexico have taken the step to implement groundwater rights systems. Well-defined groundwater use rights entitle individual users or user groups to an abstraction allocation at a certain point in time or during a specified time period. Without a clear definition of who the users are and how much water they are entitled to, the users themselves have no incentive to use the water efficiently, because they have no guarantee that if they save water today, the aquifer's yield will permit them to abstract what they need tomorrow. In addition, if water allocations are to be shifted to different users, without defined groundwater use rights, there is no information about how much can be reallocated, who would win and who would lose and how compensation might be structured. 
It is important to note that to achieve better groundwater management, groundwater use rights need not be tradable. Obviously, tradability would introduce an increased option for efficiency, but often the first, most important step is to register the users and get a better estimate of the types and magnitude of abstraction. This information can then be compared to information about aquifer recharge and thus long-term water use sustainability (Kemper, 2001; World Bank, 2002-2005).

Proponents of water trading consider tradable rights a very powerful instrument because they induce the right holder to apply a long-term perspective. The holders will consider not only what the water can directly produce for them (e.g. tonnes of rice), but also the opportunity cost of the water (e.g. the value added by using the water in car manufacturing, which is the payment that could be expected if the groundwater right were traded). Thus, the highest value of water use is taken into account and provides an incentive for more efficient use and reallocation of surplus water to a higher-valued use.

Often even without codified rights systems, both formal and informal groundwater markets have developed in water-scarce areas. However, these markets typically do not provide incentives for long-term use perspectives, because use rights are unclear. For instance, in the informal groundwater markets in Gujarat, India, water is sold without consideration of the limits of the resource, and while the allocation of the resource may be more efficient than if the markets did not exist, the groundwater level is nevertheless being drawn down. The ability to sell whatever water is pumped may even be an added incentive to overabstraction. This serves to remind that water markets are complex institutional set-ups in themselves and need substantial regulation if they are to fulfill sustainability and equity objectives. ${ }^{2}$

Further, the establishment of rights and markets does not mean they will actually be used to increase use efficiency. For example, Mexico has long had a formal groundwater market, but the market has not been very active, in part due to the transaction costs built into the system (World Bank, 2006). By contrast, the groundwater market in New Mexico, USA (which is also driven by conjunctive use regulations), is very active (DuMars and Minier, 2004). Reallocation by trading means getting compensated.

Water use rights are thus rules that need to be designed, changed and adapted to different situations. They are advocated here as a tool to provide a long-term horizon to water users. As mentioned earlier it is important to note that tradable groundwater use rights per se will not resolve overexploitation of an aquifer unless a certain percentage of the aquifer volume is reserved to achieve a certain stabilization. Theoretically, this could take place, for instance, in the same way as air pollution rights trading, where each year a certain, decreasing amount of water is designated as tradable, effectively decreasing the consumptive use on a yearly basis. This implies, however, that groundwater users forego a certain amount of water every year and thereby lose income opportunities or that they have, in the meantime, implemented more efficient technologies and therefore can accept this restriction for the good of all. It will depend on the locality-specific circumstances if groundwater users will easily come together and agree on such restrictions. For instance, 
in Mexico, groundwater management user groups, the so-called COTAS, have now existed for about 10 years, but while they have been able to promote awareness-raising activities and also, to some extent, water-saving investments, there are very few COTAS that have as yet decided to restrict total water use of the aquifer or take active steps towards its stabilization. Also in water-scarce Yemen, where a World Bank-financed project supported the introduction of more efficient irrigation water use, the Project Implementation Completion Report pointed out that while farmers readily accepted the new technologies, they tended to use the saved water to expand their planted areas, thus leading to improved livelihood for farmers in the short run, but not leading to improvement of the aquifer conditions, which will have long-term implications for the farmers (World Bank, 2001). In Arizona, USA, on the other hand, farmers have to reapply for groundwater use permits periodically, and each time the total permitted abstraction volume is adjusted downwards, based on assumed changes in technology (Jacobs and Holway, 2004). Also on the North China Plain, Foster et al. (2004a) report that agricultural water-saving measures, such as improved irrigation water distribution through low pressure pipes and drip and micro-sprinkler technology, improved irrigation forecasting, and deep ploughing, straw and plastic mulching, etc. have reduced non-beneficial evapotranspiration and led to real water savings in the order of 35-40 mm/year in various pilot areas. At the same time, farmers' incomes have increased to above the national average. Clearly, these are encouraging examples, which show that the institutional arrangements need to include not only water user participation and awareness raising, but also enforcement and sanctioning mechanisms.

In the absence of prior well metering, a pragmatic first step to assign water use rights is an initial assessment by groundwater management agencies (e.g. North China Plain) or a self-assessment by groundwater users of their historical use (e.g. Mexico). These assessments may overestimate the historical use, such as in the Mexican and Chinese cases, but groundwater administrators do accept them as a starting point. The challenge then is to eventually reduce the overall volume of rights in order to arrive at the actual amount of groundwater withdrawn. Only in this next step will groundwater use actually be decreased. This gradual decrease can only take place if the institutional framework is sufficiently developed to permit follow-up actions (e.g. re-registering of wells and permits, and use of licensed drillers). Quite clearly, this is a long-term process that requires considerable resources and, perhaps more importantly, social and political will. This latter factor can be especially problematic since costs will be more immediate than benefits.

Another important aspect in the allocation of groundwater rights is the distinction between open access and common property resources (see Schlager, Chapter 7, this volume for detail). Aquifers are a typical example of a common property resource and are often also an open access resource, when neither private nor collective groundwater use rights exist. The introduction of water use rights can remediate this situation by offering an incentive towards a longterm perspective by individuals and an interest in controlling fellow users. As pointed out previously, however, high transaction costs can be expected in the introduction of groundwater use rights due to existing vested interests by 
current users. They can be especially high if an aquifer is already overexploited and decisions for curbing groundwater use have to be taken. For this reason, it is recommendable to start groundwater management in situations that require less sacrifice, i.e. lower costs for stakeholders, and not to wait until situations become critical.

It should also be pointed out that groundwater use rights could be accorded to groups on a collective basis. The reasoning regarding incentives remains the same, i.e. if the group has a water use right, there is an interest to preserve or stabilize the aquifer on behalf of the group. Naturally, intragroup enforcement of agreed actions is also essential in this case.

\section{Groundwater use rights: enforcement, monitoring and sanctions}

The implementation and effectiveness of a groundwater use right crucially depends on enforcement capacity, sanctioning systems, water reallocation mechanisms and the need for the generation of information and its management. There is also an important linkage to pricing mechanisms (see the following section).

As mentioned earlier a key issue in groundwater management is the size of the groundwater user community. Groundwater aquifers can be very small, with only tens or hundreds of users, such as is the case for some aquifers in Mexico, California and South Africa. It is very well conceivable that users would be able to arrive at a joint management framework, even without individual property rights. As pointed out by Shah et al. (2000), many aquifers, especially in Asia, have thousands of users. In that case, it is far more difficult to envision one integrated framework at the 'community level', and obviously transaction costs for both introducing and maintaining any groundwater framework increase significantly (see also Table 8.1). In such cases, submanagement structures around subaquifer units are required. The many groundwater recharge movements in India show that even if recharge and water savings do not take place across an entire large aquifer, the local impacts can be beneficial. ${ }^{3}$

For groundwater use rights to function as management instruments, the following need to be in place:

- initial allocation;

- $\quad$ registration mechanism and maintained registry system;

- functioning monitoring system;

- $\quad$ enforcement of the limits set by the individual or communal use rights;

- credible sanctioning system.

All of the above, i.e. the individual design and the implementation, depends on the aquifer and on local or national institutional capacity. Sandoval (2004) and Jacobs and Holway (2004) describe how the administrative systems are organized in the states of Guanajuato (Mexico) and Arizona (USA), respectively, and how these states have designed their groundwater management systems around existing capacity. In the case of Arizona, the state groundwater management agency is far stronger than the one in Guanajuato. Accordingly, in 
Guanajuato an approach has been taken that strongly relies on local groundwater user groups in order to complement and enforce the groundwater permit administrative system. These examples show the local nature of designing systems to suit local conditions.

In summary, groundwater use rights are essential to provide incentives for better groundwater management, but perhaps even more than with surface water, they need to be designed in a flexible and locally adapted manner to allow for local needs and circumstances. For this, the characteristics of the aquifer, individual or common property right cultures, different lengths of validity of the rights, formality and informality as well as transferability need to be taken into account.

\section{Groundwater pricing}

When dealing with the need for more efficient groundwater use and allocation, a prime recommendation is usually the introduction of a groundwater tariff or fee. The rationale is that groundwater users have an incentive to use water efficiently when it has a price. If it is free, they will use more than they would otherwise, unnecessarily reducing the availability of water for everyone and increasing scarcity of, and thus competition for, the resource. If 'the price is right', users will have incentives to use less water and introduce water-saving technologies, thus freeing water for other uses.

In groundwater, pricing issues are distinct from surface water, given that abstraction of the groundwater resources usually takes place on private land and with private equipment. Therefore, there are actually two options for pricing: pricing the resource itself or pricing the other inputs needed in order to pump groundwater such as the pump, borehole and, most importantly, energy.

\section{Energy pricing}

The cost of energy is usually seen as the most important incentive to reduce overabstraction. Figure 8.3 depicts the Mexican situation and we can see that there was a noticeable decrease of electricity consumption in 1990, when an increase in the special rural energy tariff took place. One can infer from the results that the elasticity with regard to energy pricing in Mexico is significant, i.e. water users clearly respond to price changes that affect their energy bills. Usually, however, this type of action is not easy to apply due to political reasons - as was also the case in Mexico when the government responded to pressures and decreased the tariffs again. This is reflected in the downturn in the price curve in Fig. 8.3, and a corresponding increase in pumping from 1992 and onwards.

The Mexican situation is not unique. Many countries subsidize agricultural inputs and, among them, rural energy (e.g. a number of states in India, Brazil, etc.). Once this has happened, it is politically very difficult to return to, or start implementing, energy prices that actually reflect the cost of energy to the state. The effect is not only a clear incentive for groundwater overabstraction, but also important fiscal implications for the state. Depending on the cal- 


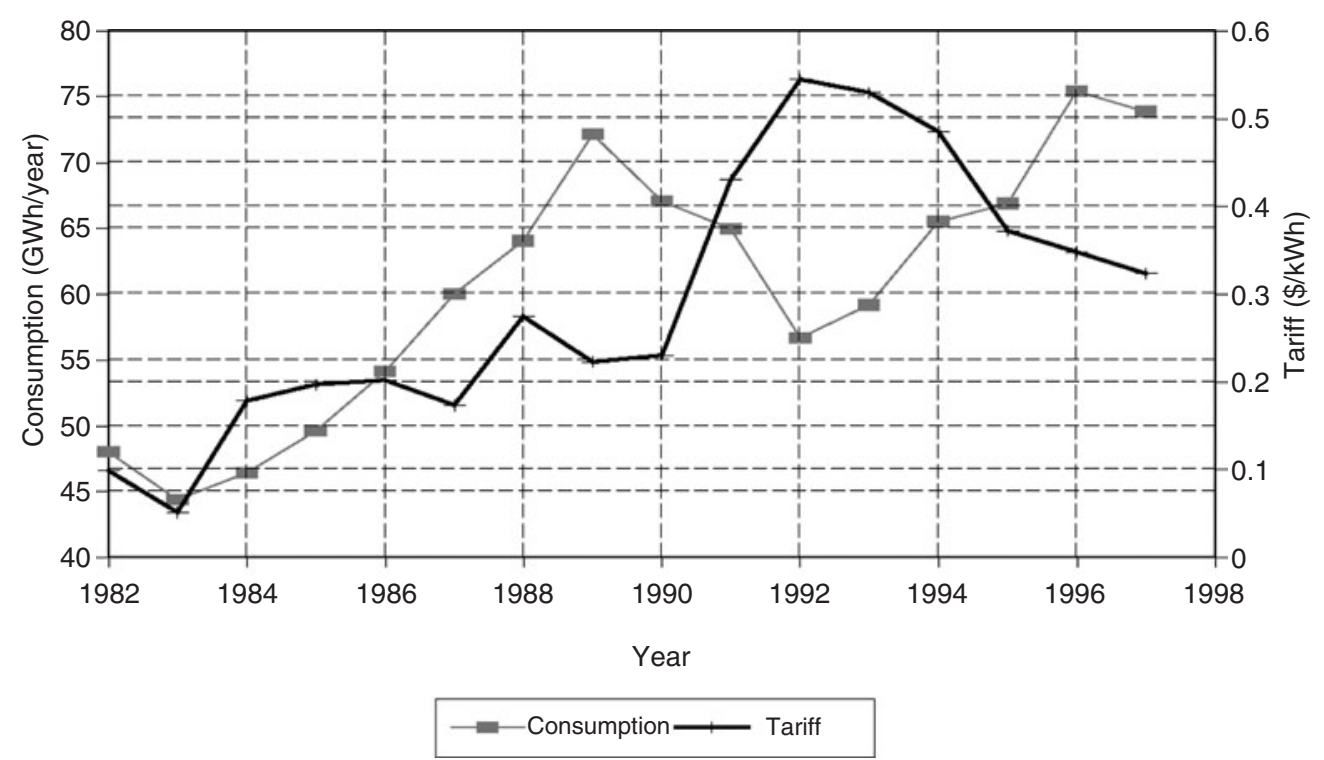

Fig. 8.3. Relationship between electricity tariff and consumption in Mexico, 1982-1997.

culation method, energy subsidies to agriculture in India amount to between $\$ 1.9$ billion and $\$ 6.5$ billion per year (Bhatia, 2005). ${ }^{4}$ At the all-India level, electricity subsidies to agriculture are estimated at $26 \%$ of gross fiscal deficit. They may vary from $80 \%$ in Madhya Pradesh and Haryana to 50\% in Andhra Pradesh, Gujarat and Karnataka, and to about $40 \%$ in Rajasthan, Punjab and Tamil Nadu (Bhatia, 2005). ${ }^{5}$

Even here innovative ways need to be sought. While energy pricing is seen by many politicians as an effective means to subsidize rural producers - and therefore a number of countries even apply zero tariffs (e.g. the states of Tamil Nadu and Andhra Pradesh in India reverted to zero tariffs after the elections in May 2004 (Bhatia, 2005)) - the detrimental effect on groundwater aquifers needs to be taken into account. ${ }^{6}$ The well-intentioned 'pro-poor' policy may eventually turn into an 'anti-poor' policy when the aquifers become overexploited and only the rich can afford to continue pumping. That is why other types of subsidies should be contemplated. An option could, for instance, be lump sum payments to small farmers that would permit them either to pay the full electricity bill or to reduce their pumping, pay a lower bill and use the 'gain' for something else. In this way the energy tariff would not distort the true price of groundwater, and at the same time not hurt the poor (World Bank, 2006).

\section{Pricing the groundwater resource}

Another way to provide an incentive to use water more efficiently is to price the resource itself, i.e. users pay for the abstraction of the groundwater resource itself. For the maximum impact, this should be based on volumetric metering, thus providing an incentive to use less water. Many times, however, metering equipment is not installed on wells or it is not effectively monitored by 
the (ground)water management agency. Therefore, few countries practise direct groundwater pricing, especially in agriculture where there tend to be large numbers of users, and transaction costs for monitoring are disproportionately high. In some countries, e.g. Mexico and France, industrial and municipal users pay, but because agricultural users are exempt and they use the largest share of the water, the impact on the groundwater resource is little.

Due to the cost of monitoring individual wells - and also due to the possibilities of corruption in meter reading or tampering - there are now efforts to develop remote-sensing tools, which can help calculate groundwater use based on the observed crop cover. The advantage of these tools is their visual power and the fact that water users themselves can learn to interpret them. This affords the possibility for aquifer self-management rather than reliance on well-by-well monitoring, thus increasing transparency in aquifer management and reducing strategic transaction costs. By using remote-sensing information, users can monitor each other's groundwater use, for example, by comparing neighbours' type of crops and area under cultivation, enabling peer pressure to enforce abstraction agreements (including use efficiency) and reducing possibilities of shirking.

In spite of some caveats (e.g. how to accurately model and calculate evapotranspiration), remote sensing can develop into an important and increasingly affordable tool for groundwater management. Attempts at its use are taking place, for instance, in Idaho, USA, and in South Africa.

Another option is self-declaration as practised in New Mexico and in Arizona, USA. In these states groundwater users declare once a year what their actual abstraction has been. In Arizona, every time a permit expires, it is reconsidered from a technical point of view and the new permit will be issued taking into account the potential water savings that the user could make by installing more efficient irrigation technology. This way, total abstraction from the state's aquifers is brought down over time (Jacobs and Holway, 2004). South Africa also uses self-declaration.

\section{Subsidies for technological improvements}

As mentioned earlier, a further instrument to improve groundwater management in agriculture consists of subsidies to improve irrigation efficiency by farmers' investments in better technology. This may imply support to make investments in closed conveyance pipes instead of earth canals that are subject to evaporation, shifting from flood irrigation to drip irrigation and investments in soil levelling, mulching, etc. There are a number of examples worldwide showing that these approaches work from the technological point of view, as in China, Mexico and Yemen. However, such measures will only be effective if farmers do not at the same time expand their fields or increase their cropping cycles. The incentive to do so and to improve one's individual livelihood is significant; therefore, understanding of the reasons for these subsidies and enforcement plays an important role. 


\section{Groundwater Management Organizations - Participation, Information and Awareness Raising}

As has become clear from the earlier discussions, a number of instruments exist to introduce more efficient groundwater use and allocation. These range from effective monitoring to defining groundwater use rights and to pricing the resource.

At the same time, the effectiveness of any of the instruments employed in a given situation will depend on the organizational set-up for groundwater management. Groundwater is distinct from surface water in that many different users are involved in abstracting the resource, and monitoring their individual behaviour is very costly. Users, of course, are very well aware of this fact, and therefore their incentive to comply with metering regulations and with prohibitions against sale/lease of water or tariff payments is typically very low.

Experience from many countries has shown that actively involving stakeholders, and providing them with information and with a say in the management of their resource, is essential to create incentives for compliance, be it in regard to groundwater or to surface water management. As previously mentioned, the COTAS in Mexico have had a very important role in raising awareness and providing information to groundwater users. As pointed out by Foster et al. (2004b):

[The] fundamental goal of the COTAS (as conceived) is to provide the social foundation to promote measures to slow down, and eventually eliminate, aquifer depletion. It is clear from the experience to date that the COTAS cannot achieve this goal alone - but neither could the 'water administration' achieve it without the COTAS.

The Government of Jordan came to the same conclusion when well abstraction limits were not followed by users, and it started implementing a promising, stakeholder-based approach (Chebaane et al., 2004). The experience of river basin organizations worldwide (although not focused on groundwater) has shown the power of information and of stakeholder involvement in achieving better water resource management performance (Dinar et al., 2005).

The reasoning is simple: (ground)water users who do not know what the conditions of their resource are will be less willing to sacrifice their current income than those who are aware that overexploitation is going to hurt them in the foreseeable future. For this, they need comprehensible and reliable information and a voice in shaping the institutional framework.

Blomquist (1992) provides a comprehensive description and analysis of the development of local management structures in eight Californian groundwater basins. Interestingly, each development started with (i) the recognition that the groundwater resource was under increasing stress (as noticed by sinking water levels and sometimes saltwater intrusion) and (ii) the collection of data about the aquifer, its recharge and potential safe yield. Once the data were obtained and confirmed on the ongoing overdraft, water users were able to forecast the potential consequences of non-action and started to organize for more sustainable use and management of their aquifers. 
These examples illustrate that groundwater users need to be recognized as true stakeholders who are entitled to information about the resource they are so dependent on. For many water agencies, this implies a significant shift, not only in technology, from being centralized agencies that keep the information about water availability to themselves and take decisions without the participation of other stakeholders. Obviously, the trend towards definition and official allocation of (ground)water use rights (such as in Brazil, Chile, Mexico and South Africa) contributes to a move towards transparency. Information is essential for decision making among all levels of stakeholders to determine what planning horizon to consider, which savings measures to propose and accept, what investments to make as well as what service to require from water agencies and government authorities. With a better-defined basis of groundwater use rights - and responsibilities - information becomes more valuable and more crucial to the different stakeholders.

A number of countries, including the USA, Mexico and India are thus moving towards the management of aquifers by groundwater user associations of various types, in an attempt to involve users in decision making and increase compliance with decisions that have been taken collectively. In those cases, these developments are accompanied by a range of other demand management instruments discussed in this chapter. In the USA, this shift has been taking place over the last five decades and is showing good results (Blomquist, 1992; Jacobs and Holway, 2004; Sandoval, 2004). This topic is presented in depth by Schlager (Chapter 7, this volume) on community participation and communal approaches.

\section{Conjunctive Use of Surface and Groundwaters}

\section{Groundwater use within surface water irrigation projects}

As outlined at the beginning of this chapter, groundwater management is often treated as if it took place in areas distinct from surface irrigation schemes. However, when looking at many such schemes, ranging from India to Pakistan and Mexico, farmers actually use surface and groundwaters in conjunction. This implies that groundwater use is probably even more widespread than it seems. Many times farmers use groundwater because surface water schemes are not functioning, not delivering water on time or not timely enough to grow sensitive (and often high-value) crops. If groundwater were managed better and surface water more effectively - significant benefits could be achieved.

One of the key disadvantages of unmanaged conjunctive use is that without control, groundwater use is usually concentrated at the tail ends or around the margins of surface water irrigation areas. This is suboptimal because excessive groundwater abstraction here often aggravates natural salinity problems, and meanwhile excessive groundwater laminae in the main riparian areas can cause rising water tables and water logging. Planned conjunctive use would optimize the situation by spreading both uses.

Obstacles to managed conjunctive use include distortions between surface and groundwater abstraction costs. Why would farmers upstream - where 
they receive abundant surface water through their irrigation canals - want to irrigate with groundwater, which would be far more expensive than the highly subsidized surface scheme only to benefit the tail-end farmers? Often there are also legal impediments to doing so. Therefore, the incentive structure needs to be examined in order to move towards more sustainable management of the physical system.

\section{Agricultural water use in highly populated regions}

There is evidence from the North China Plain, where the growth of small towns that are reliant on groundwater for their populations and industries is significant, that the impact on the - rapidly diminishing - groundwater source is large (Foster et al., 2004a). In such situations a groundwater management strategy needs to take into account both agricultural and urban uses. Similarly, interaction between surface water and groundwater needs to be taken into account (e.g. the Rio Grande in New Mexico) in providing new permits for surface water abstractions since there will be impacts on groundwater abstractors.

Nevertheless, an important issue in this regard is the recurring assertion that since surface and groundwaters are hydrologically connected, aquifers cannot be managed in isolation. This argument is relatively weak, however, given that in many cases surface waters are managed - if at all - without ever taking into account the connected groundwater resources. Thus, while the principle to apply a conjunctive management approach is desirable, nowadays many aquifers are under such pressure that pragmatism would dictate tackling them directly, without neglecting basic principles of integrated groundwater management as identified in the course of time (Kemper and Alvarado, 2001; Foster et al., 2004b). Thus, in cases in which the hydrological connection to surface water resources is very significant, conjunctive use could and should appropriately be taken into account - such as in New Mexico, USA (DuMars and Minier, 2004) - but the pros and cons of doing so need to be carefully assessed.

\section{Groundwater Quality Management}

Management of groundwater quality in an agricultural context has several dimensions: the pollution caused by agriculture (e.g. salinization due to fertilizer use, contamination of groundwater by pesticides, overpumping of coastal aquifers and sea water intrusion, overabstraction of aquifers with underlying saline water); and the pollution caused by other actors, but with a negative impact on water quality also for irrigators.

In terms of the management instruments to be used in the first case, these range from educating farmers about the appropriate amounts of fertilizers and options for integrated pest management to avoid contamination of the groundwater to phasing out certain products, to increasing prices of harmful products in order to discourage their use. Unfortunately, non-point source pollution is very difficult to manage and there are not many successful examples. 
With regard to salinization due to overabstraction, the same approaches as discussed earlier apply: groundwater abstractors need to be made aware of the problem, solutions need to be developed and a number of instruments are available - ranging from peer pressure to introduction of groundwater use rights and pricing instruments - to curb demand. Unfortunately, salinization is reversible only at enormously high costs and should therefore be avoided rather than mitigated.

The pollution by growing urban centres and industries is not the topic of this chapter; therefore suffice it to say that even here integrated approaches are needed and that with growing populations, especially in Asia, the interface between urban and agricultural water quality management is becoming more pronounced.

\section{Conclusion - Is Groundwater Manageable?}

Groundwater management was neglected for a long time due to the apparent abundance of the resource. With population and economic growth and the technological options to abstract groundwater at reasonable prices from ever-greater depths, the need to actively manage the resource has become clear. This is especially the case in developing countries where the poorer segments of rural society do not have other livelihood options available, should they lose access to their safe water source, both regarding production and drinking water supply.

This chapter argues that institutional frameworks for groundwater management need to comprise a range of instruments to manage the resource. Contrary to a mechanistic belief, however, the need to fully integrate the human dimension is highlighted. Thus, the creation of incentives through the introduction of groundwater use rights, direct and indirect pricing, or water trading is an important step. However, the horizontal dimension of groundwater use makes it hard to fully control the application of such instruments unless a given aquifer has very few users and the responsible authority, a very clear mandate and sufficient capacity. In most cases, the users themselves are the most important stakeholders in devising groundwater management schemes as well as in devising and choosing the most applicable instruments.

As countries move towards actively managing their groundwater resources, their approaches are taking this interplay into account. Some countries rely more strongly on formal institutional arrangements such as regulations and official monitoring and sanctioning mechanisms; others try to combine both formal arrangements and informal water user agreements; and still others focus primarily on water users in order to deal with their specific groundwater management challenges. The choice of these approaches is related not only to the institutional strengths in the individual countries but also to the type of hydrogeological regime and population and economic profile they have to deal with.

While there are very few success stories as yet - and these are essentially in developed countries - increasing groundwater scarcity and pollution are providing an impulse for central and local governments worldwide to introduce 
groundwater management frameworks and instruments, adapted to their needs. The toolbox for groundwater management already exists. Now the political will needs to be developed in order to bring about - or intensify - change. This will imply reviews of existing groundwater management structures, the costs that current institutional arrangements have for specific groups in the medium and long terms as well as the costs to society at large. This information needs to be made available to decision makers to provide an impetus for the use and further development of existing groundwater management tools.

\section{Acknowledgements}

The author would like to thank Stephen Foster and Barbara van Koppen for their very useful review comments and the Groundwater Management Advisory Team of the World Bank/GWP for the many valuable discussions over the years that have influenced the content of this chapter.

\section{Notes}

1 Each state in the USA has a different system.

2 See Mariño and Kemper (1999) for an in-depth analysis of water markets and the needed institutional arrangements to make them function.

3 Although recently concerns have been voiced that groundwater recharge in an upstream area, due to water-harvesting structures, may impede flow to downstream areas, effectively leading to a reallocation of the water resource. This issue needs further study.

4 That is, Rs 80 billion and Rs 281.2 billion, respectively (Rs/\$ exchange rate used 43:1).

5 According to Bhatia (2005), these estimates may be on the higher side, given that State Electricity Boards tend to lump transmission losses into agricultural subsidies. Nevertheless, the subsidies do constitute a large part of the states' deficits, illustrating that not only the groundwater situation, but the entire states' finances are affected.

6 Politically, an important issue relates to the fact that groundwater users point out that surface water users are usually highly subsidized because frequently neither the capital nor the operation and maintenance costs of surface water irrigation systems are recovered. Accordingly, this leads to a political dilemma, with groundwater users questioning why they should be paying higher prices for water than surface water users do.

\section{References}

Bhatia, R. (2005) Water and energy, Background Paper for the report India's water economy: bracing for a turbulent future. World Bank, 2006.

Blomquist, W. (1992) Dividing the Waters: Governing Groundwater in Southern California. ICS Press, San Francisco, California.
Brown, L., Gardner, G. and Halweil, B. (1999) Beyond Malthus. The Worldwatch Environmental Alert Series, Worldwatch Institute, Washington, DC.

Chebaane, M., etal. (2004) Participatory groundwater management in Jordan: development 
and analysis of options. In: Kemper, K.E. (ed.) Groundwater - From Development to Management. Hydrogeology Journal Theme Issue, Springer, New York/The World Bank, Washington, DC.

Dinar et al. (2005) Decentralization of River Basin Management: A Global Analysis. Policy Research Working Paper No. 3637. The World Bank, Washington, DC.

DuMars, C.T. and Minier, J.D. (2004) The evolution of groundwater rights and groundwater management in New Mexico and the Western United States. In: Kemper, K.E. (ed.) Groundwater - From Development to Management. Hydrogeology Journal Theme Issue, Springer, New York/The World Bank, Washington, DC.

Foster, S.S.D., et al. (2004a) Quaternary aquifer of the North China Plain - assessing and achieving groundwater resource sustainability. In: Kemper, K.E. (ed.) Groundwater - From Development to Management. Hydrogeology Journal Theme Issue, Springer, New York/The World Bank, Washington, DC.

Foster, S., Garduño, H. and Kemper, K. (2004b) The 'COTAS' - Progress with Stakeholder Participation in Groundwater Management in Guanajuato-Mexico. GWMATE Case Profile Collection, No. 10. World Bank, Washington, DC. Available at: www.worldbank.org/gwmate

Jacobs, K. and Holway, J.M. (2004) Managing for sustainability in an arid climate: lessons learned from 20 years of groundwater management in arizona, USA. In: Kemper, K.E. (ed.) Groundwater - From Development to Management. Hydrogeology Journal Theme Issue, Springer, New York/The World Bank, Washington, DC.

Kahnert, F. and Levine, G. (1993) Groundwater Irrigation and the Rural Poor: Options for Development in the Gangetic Basin. The World Bank, Washington, DC.

Kemper, K.E. (2001) Markets for Tradable Water Rights. Overcoming Water Scarcity and Quality Constraints. 2020 Focus 9, Brief 11. IFPRI, Washington, DC.

Kemper, K.E. (2003) Rethinking groundwater management. In: Figuères, C., Rockström, J. and Tortajada, C. (eds) Rethinking Water Management: Innovative Approaches to Contemporary Issues. Earthscan, London.

Kemper, K.E. and Alvarado, O. (2001) 'Water,' in Mexico: a comprehensive development agenda for the new era. In: Giugale, M., Lafourcade, O. and Nguyen, V. (eds) Policy Notes. The World Bank, Washington, DC.

Mariño, M. and Kemper K.E. (eds) (1999) Institutional Frameworks in Successful Water Markets - Brazil, Spain and Colorado/USA. The World Bank, Washington, DC.

North, D.C. (1990) Institutions, Institutional Changes and Economic Performance. Cambridge University Press, Cambridge.

Sandoval, R. (2004) A participatory approach to integrated aquifer management: the case of Guanajuato state, Mexico. In: Kemper, K.E. (ed.) Groundwater - From Development to Management. Hydrogeology Journal Theme Issue, Springer, New York/The World Bank, Washington, DC.

Shah, T., et al. (2000) The Global Groundwater Situation: Overview of Opportunities and Challenges. International Water Management Institute (IWMI). Colombo, Sri Lanka.

World Bank (2001) Yemen - Land and Water Conservation Project, Vol. 1. Project Completion Report. The World Bank, Washington, DC.

World Bank (2002-2005) Sustainable Groundwater Management - Concepts and Tools. Groundwater Management Advisory Team (GWMATE) Briefing Note Series, Note 1. Washington, DC.

World Bank (2003) Environmental Protection and Sustainable Development of the Guarani Aquifer System Project. Appraisal Document. The World Bank, Washington, DC.

World Bank (2005) Pakistan Country Water Resources Assistance Strategy. Pakistan's Water Economy: Running Dry. Washington, DC.

World Bank (2006) Analisis comparativo de politicas relacionadas con el sector agua: exploracion sobre los impactos en la productividade del agua. Working Paper No. 2. Serie de Agua de Mexico. Report No. 36854.

Available at: www.wateryear2003.org 